\title{
Impacted Mandibular Premolar Concomitant with Compound- Complex Odontome in a 13-year-old Girl: A Case Report
}

\author{
Vipin R Ahuja ${ }^{1}$, Rashmi Jayanna ${ }^{2}$, Annapurna Ahuja ${ }^{3}$, Supreeya Patel ${ }^{4}$
}

\begin{abstract}
Odontomas, the benign odontogenic tumors of epithelial and mesenchymal origin, are very common in occurrence and are now widely accepted as hamartomas. Odontomes are invariably composed of enamel and dentin, and may also have variable amounts of cementum and pulp. Largely, odontomas have been categorized into the compound and complex varieties. Compound odontoma epitomizes itself as aberrations with the presence of all types of dental tissues and showing an orderly distribution in the form of tooth-like structures; whereas complex odontoma describes itself as aberrations in which the presence of some or all dental tissues and in a disorganized distribution. Herein, a case of compound-complex odontome associated with the impaction of a mandibular second premolar is being presented in a 13-year-old girl.
\end{abstract}

Keywords: Complex odontoma, Compound odontoma, Hamartoma, Impacted tooth, Odontoma.

International Journal of Clinical Pediatric Dentistry (2020): 10.5005/jp-journals-10005-1858

\section{INTRODUCTION}

Odontomas are perpetually the common odontogenic tumors seen in the jaw. Odontomas are a developmental defect of hard dental tissues. ${ }^{1-5}$ They have been classified as benign, tumorlike odontogenic lesions (hamartoma) ${ }^{6}$ and they institute about $22 \%$ of all the odontogenic tumors of the jaw. Paul Broca in 1867 introduced the terminology, "Odontome" and defined it as a "tumor formed by overgrowth or transitory of complete dental tissue". It is asymptomatic, non-aggressive, slow-growing, and benign in nature. These tumors are invariably composed of enamel and dentin, and may also have variable amounts of cementum and pulp. $^{7}$

Odontomas have been categorized into the compound and complex varieties. Compound odontoma epitomizes itself as aberrations with the presence of all types of dental tissues and showing an orderly distribution in the form of tooth-like structures; whereas complex odontoma describes itself as aberrations in which the presence of some or all dental tissues and in a disorganized distribution. ${ }^{8}$ Based on morphology, compound odontoma is further classified into denticular, particulate, and denticuloparticulate. Denticular variety has two or more separate denticles, each resembling a tooth; particulate variety has two or more separate masses of particles with dental tissues abnormally arranged; denticuloparticulate variety has denticles and particles present side by side. ${ }^{9}$ Junquera et al. ${ }^{10}$ clinically subdivided odontomes into central (intraosseous) odontoma, peripheral (extraosseous or soft tissue) odontoma, and erupted odontoma. Radiologically, tumors show a well-defined radiopacity surrounded by a radiolucent halo in the bone, classically embraced by a thin sclerotic line. Three developmental stages can be recognized; the first stage shows radiolucency; the second stage shows partial calcification, and the third stage shows tissue calcifications predominantly with the adjacent radiolucent halo. ${ }^{2}$

The etiology of these malformations is unknown, though local trauma, infection, and genetic factors have been proposed as significant causes in various studies. The growth is slow and asymptomatic. Hence, odontomas are commonly diagnosed in a routine radiological investigation in the second and third decades
1,2,4 Department of Pediatric and Preventive Dentistry, Hazaribag College of Dental Sciences, Demotand, Hazaribagh, Jharkhand, India

${ }^{3}$ Department of Periodontics and Implantology, Hazaribag College of Dental Sciences and Hospital, Hazaribagh, Jharkhand, India

Corresponding Author: Vipin R Ahuja, Department of Pediatric and Preventive Dentistry, Hazaribag College of Dental Sciences, Demotand, Hazaribagh, Jharkhand, India, Phone: +91 9910178102, e-mail: drvipinahuja@gmail.com

How to cite this article: Ahuja VR, Jayanna R, Ahuja A, et al. Impacted Mandibular Premolar Concomitant with Compound-Complex Odontome in a 13-year-old Girl: A Case Report. Int J Clin Pediatr Dent 2020;13(6):729-733.

Source of support: Nil

Conflict of interest: None

of life. Compound odontomas are largely found in the areas of the upper incisors and canines, followed by posteroinferior regions. Complex odontomas are more commonly found in the area of the second and third lower molars. ${ }^{5}$

Herein, we report an atypical case of compound-complex odontome associated with the impaction of the mandibular second premolar.

\section{Case Description}

A 13-year-old girl reported to the Department of Pediatrics and Preventive Dentistry, Hazaribag College of Dental Sciences and Hospital, Hazaribag, with a chief complaint of missing left lower posterior tooth for 4 years. According to the patient's parents, there was no evident history of trauma and medications, and the patient had good general health. Extraoral examination showed no asymmetry. Intraoral examination revealed clinically missing left lower mandibular second premolar with normal colored buccal mucosa at the relevant site (Fig. 1). During the clinical examination, no facial asymmetry was detected extraorally (Fig. 2). Intraoral examination revealed a permanent dentition period and the unerupted left mandibular second premolar (Fig. 3). The adjoining 


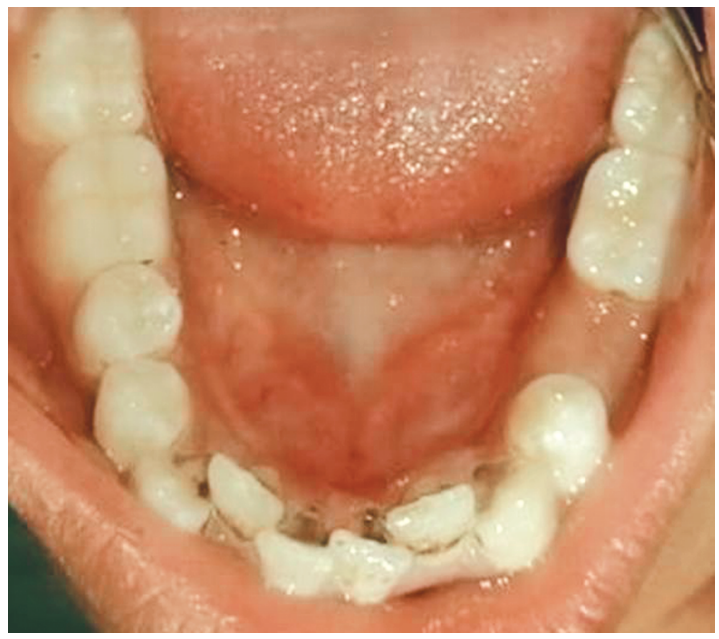

Fig. 1: Clinically missing mandibular second premolar

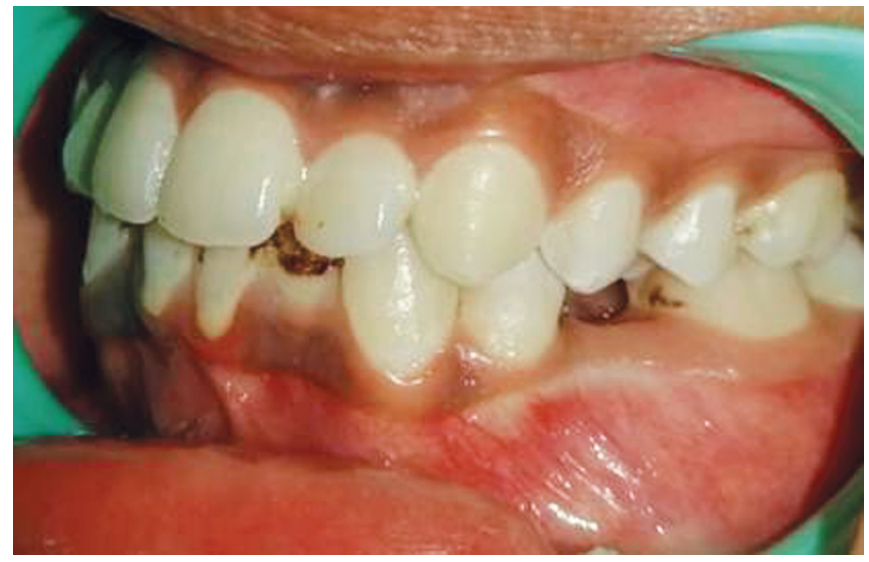

Fig. 3: Intraoral examination

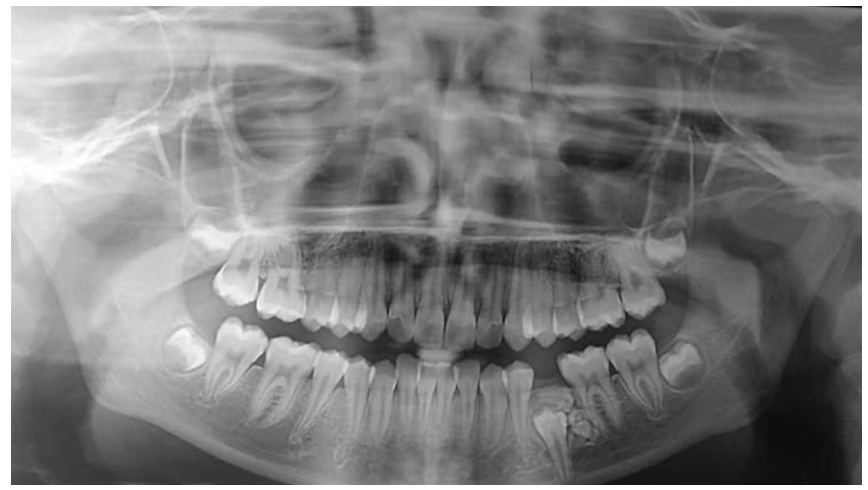

Fig. 5: Orthopantomograph

mucosa was normal, and there were no signs of redness, ulceration, pain, or swelling. On radiological inspection, a radiopaque mass was observed consisting of multiple miniatures tooth-like structures located in the superior and distal aspect of impacted 35 (left mandibular second premolar) (Figs 4 and 5). The surgical removal was planned under local anesthesia in the department of pediatric and preventive dentistry, Hazaribag College of Dental Sciences and Hospital, Hazaribagh. A mucoperiosteal flap on the buccal and lingual surfaces of the mandibular left premolar and molar teeth

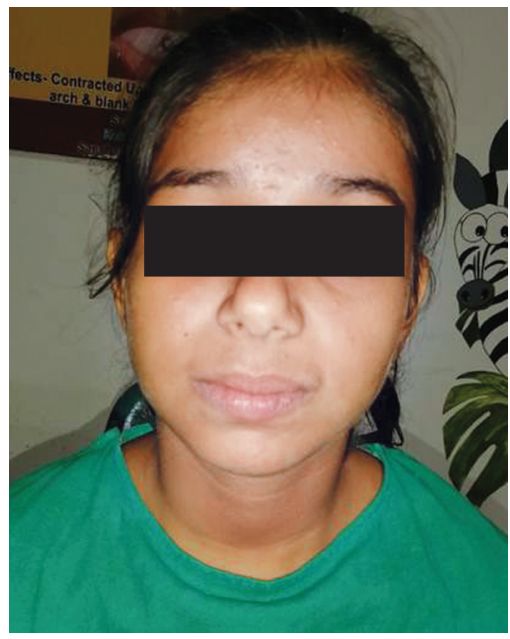

Fig. 2: Extraoral examination

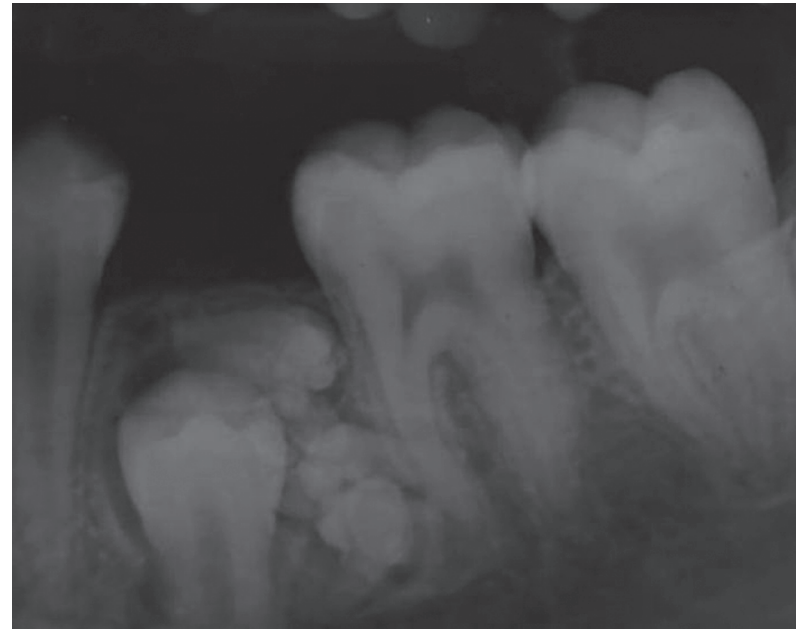

Fig. 4: Intraoral periapical radiograph

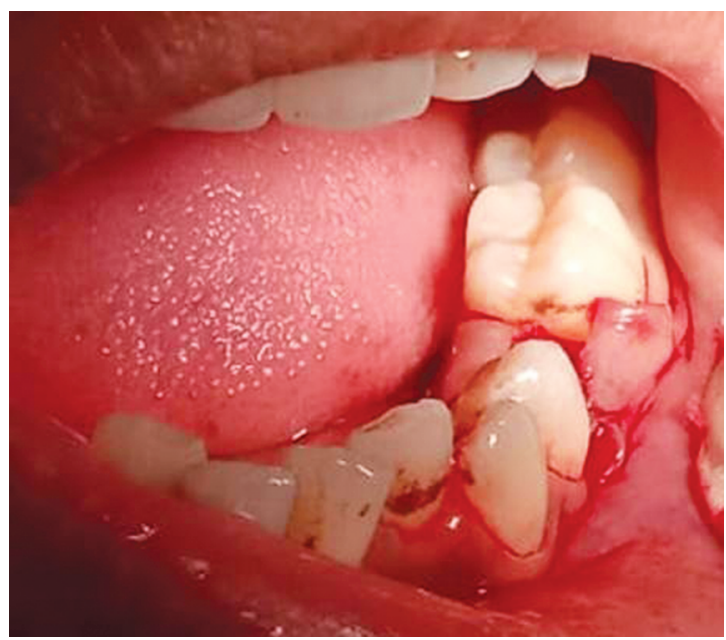

Fig. 6: Raising of mucoperiosteal flap

was reflected (Fig. 6). A window was made at the surgical site with bone-cutting burs and the rudimentary denticles were exposed (Fig. 7). The tooth-like structures were removed without causing 


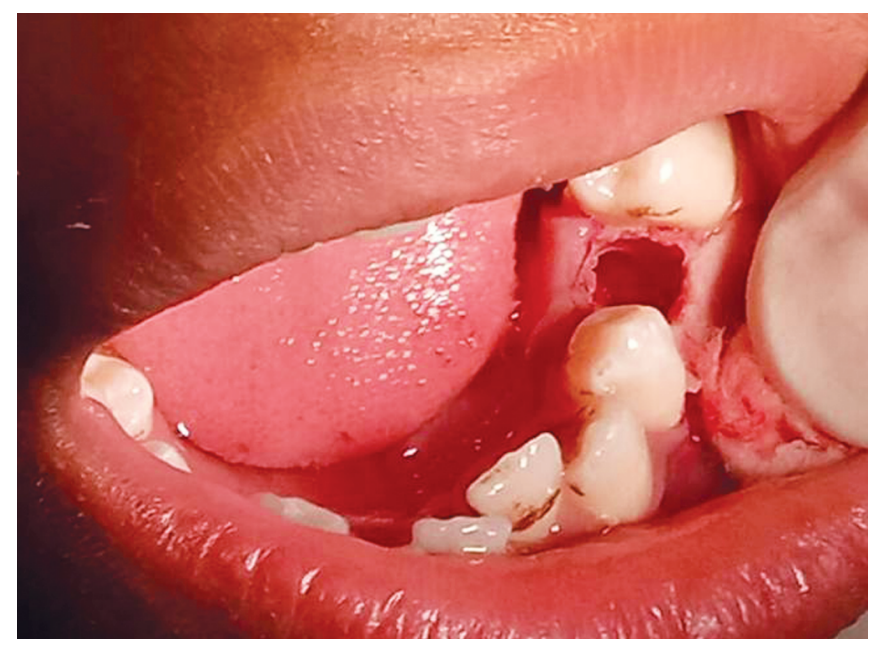

Fig. 7: Preparation of surgical window

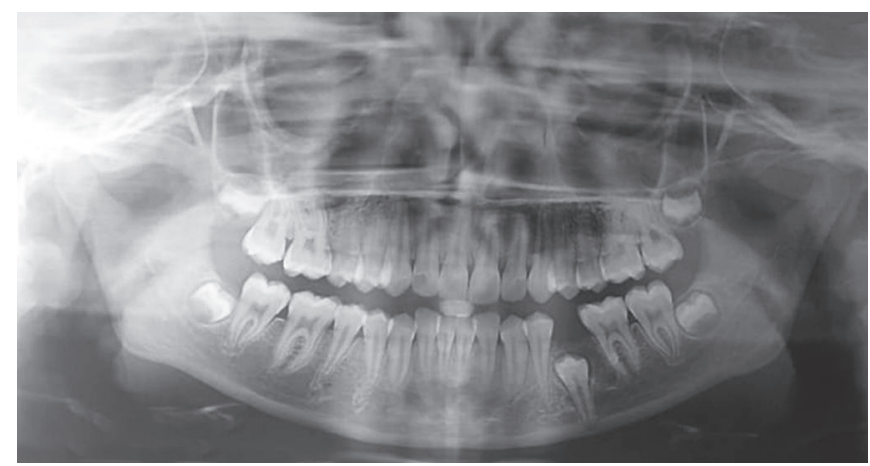

Fig. 9: One odontoma left near the mesial root of 36

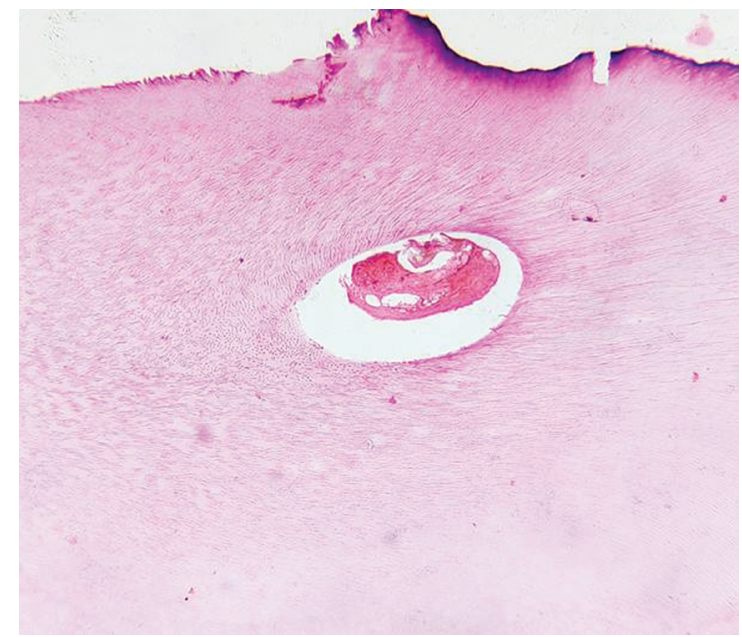

Fig. 11: Histopathological II

any harm to the underlying teeth and the removed assemblies were sent for histopathological examination (Fig. 8). Macroscopic examination revealed four miniature tooth-like structures appearing like compound odontomes and five irregular masses resembling complex odontomes. One odontome was intentionally left due to its proximity to the mesial root of 36 (Fig. 9). The surgical flap was repositioned and sutured aptly in place. Histological examination of the decalcified section revealed two types of odontomes: (1) With enamel, dentinoenamel junction, dentin, pulp,

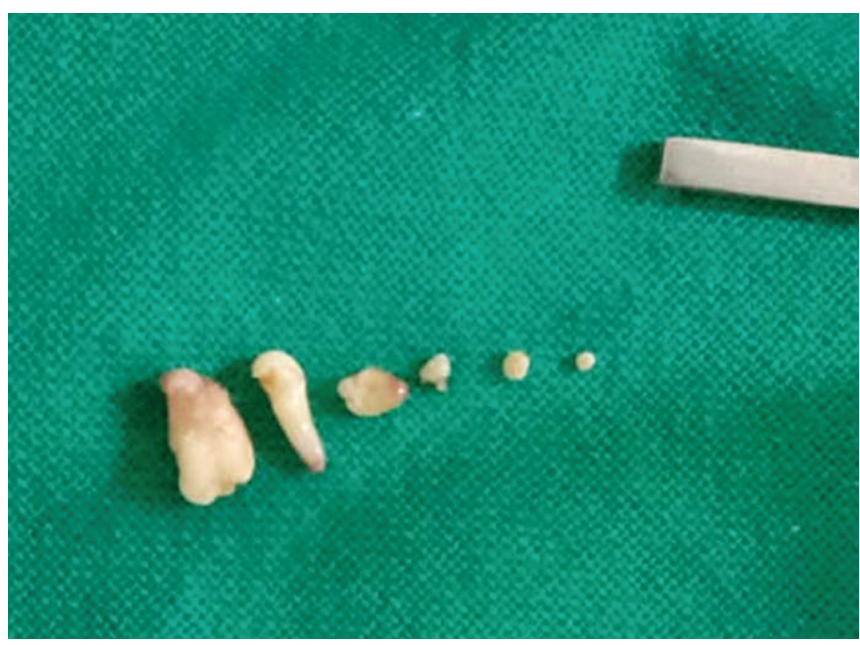

Fig. 8: Retrieved tooth-like structures

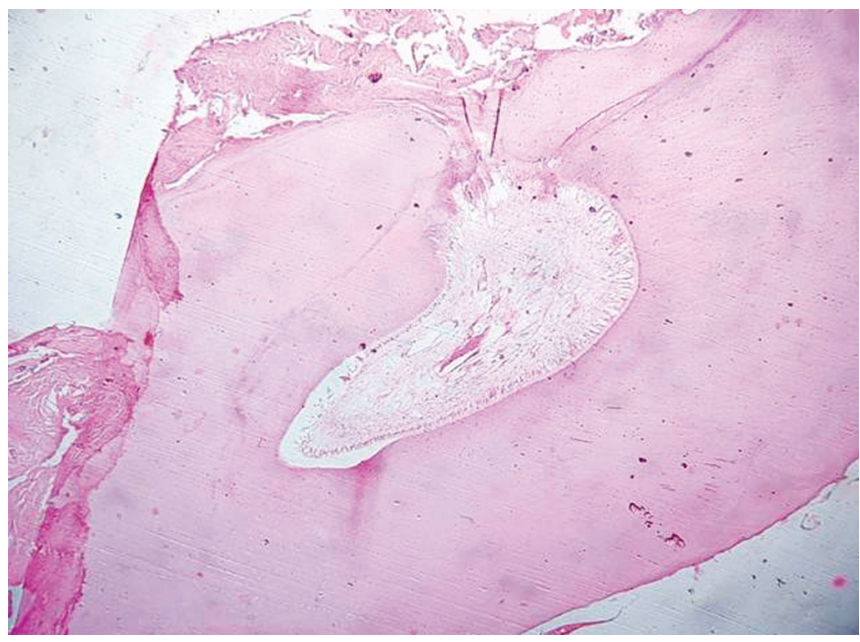

Fig. 10: Histopathological I

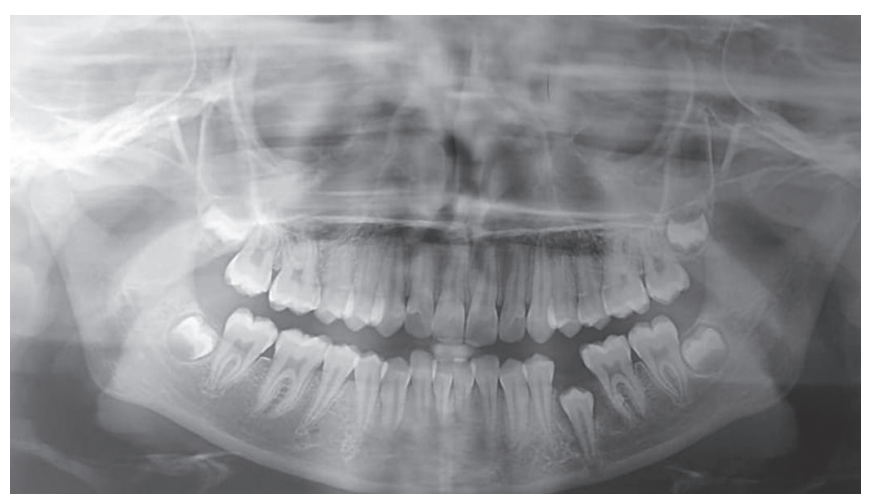

Fig. 12: OPG after 1 month

and the cementum in a way alike to normal tooth considering it as compound odontome. (2) With enamel space, pulp, and cementum considering it as complex odontome (Figs 10 and 11).

A final diagnosis of compound-complex odontoma was made based on the all above-mentioned findings. The patient was called after 10 days for suture removal. The impacted premolar was observed erupting radiographically through the alveolar bone. The patient was kept under regular observation for 1 month (Fig. 12), 3 months (Fig. 13), and 6 months (Fig. 14) postoperatively. The 


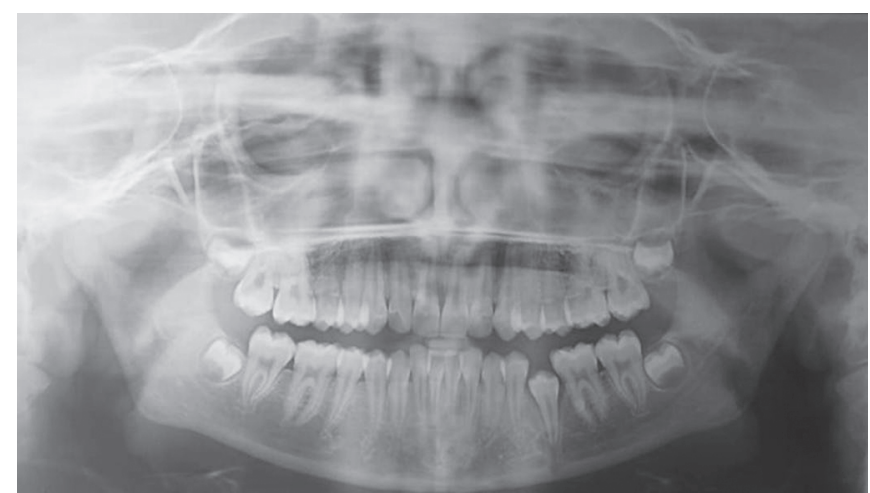

Fig. 13: OPG after 3 months

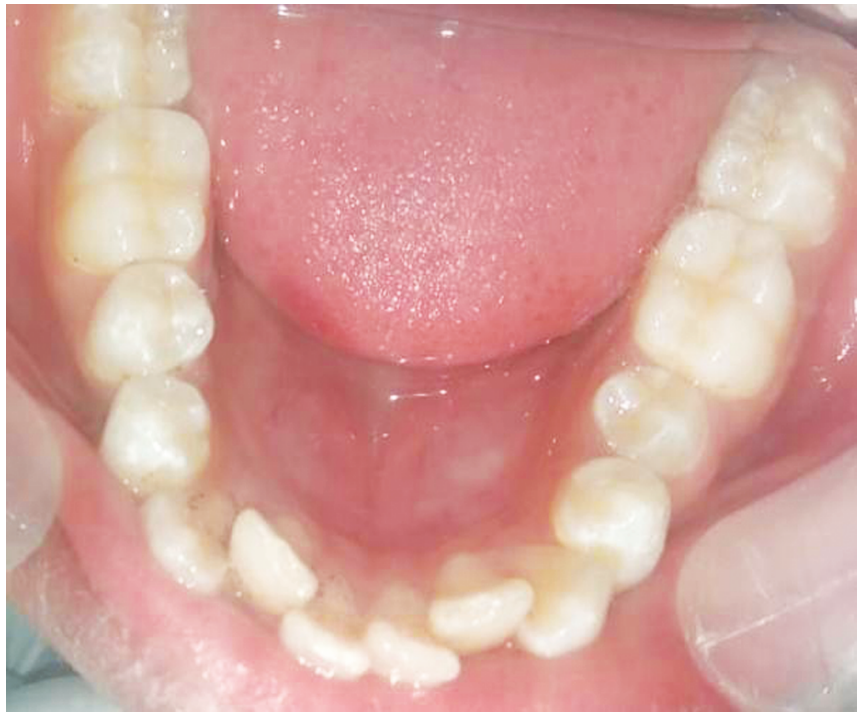

Fig. 15: Clinical picture after 6 months

impacted premolar was erupted clinically in its normal position by the end of 6 months postoperatively (Fig. 15).

\section{Discussion}

There is a plethora of literature to support that odontomes are invariably the furthermost common odontogenic tumors of the oral cavity. They are benign, generally asymptomatic tumors that have differentiated enough to form enamel and dentine. It had been proposed in various writings that as the organization of odontogenic cells abort to reach the normal stage of morphodifferentiation, the enamel and dentin tissues are laid down in an aberrant manner. For this reason, odontomes are recognized widely as developmental anomalies rather than true neoplasm. ${ }^{1-7}$

The incidence of odontomes is common in permanent dentition than primary teeth. ${ }^{5}$ The patient in our case is a 13-year-old girl, agreeing with the majority of reported cases, where tumors were seen more frequently in the first two decades of life. ${ }^{5,11,12}$ The compound odontome is most habitually seen in the incisor and canine region of the upper jaw as and when compared to complex odontome which is commonly observed in the first and the second molar region of the lower jaw. Both types of odontomes occurred most frequently on the right side of the jaw than the left. ${ }^{13,14}$ However, our case was reported on the left side of the jaw with both

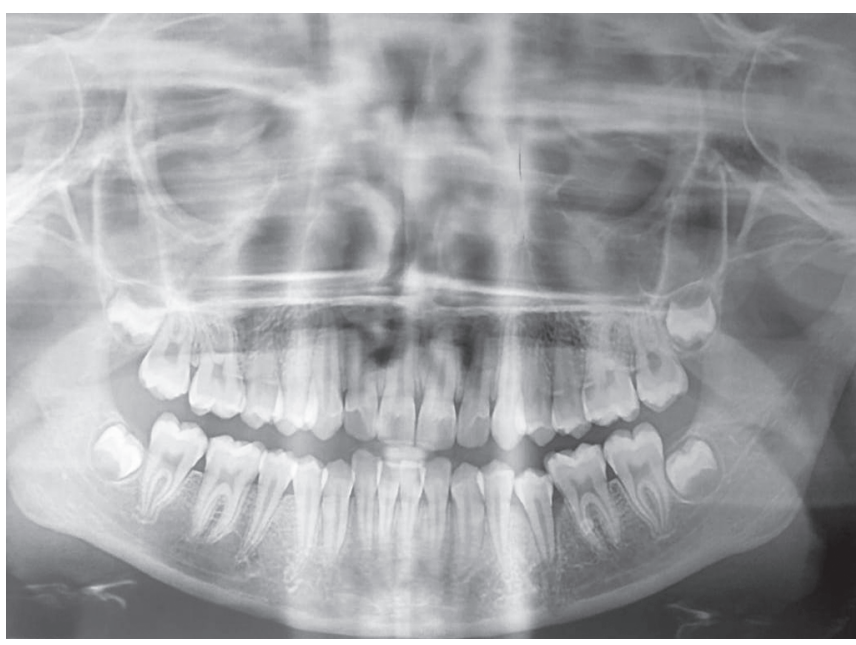

Fig. 14: OPG after 6 months

compound and composite odontomes together in the premolar region which is a peculiar finding.

Majorities of odontomas are asymptomatic as seen in our case, but sometimes pain, swelling, infection, and regional lymphadenopathies have also been reported in the literature. Radiologically, odontomes show a well-defined radiopacity surrounded by a radiolucent halo in the bone, classically embraced by a thin sclerotic line. Compound odontomas show an ill-defined radiopaque image made up of multiple radiopacities, which relate to the so-called denticles. Complex odontomas show a nonspecific radiopacity with irregular, single, or multiple disorganized masses. ${ }^{1,15-20}$

Histological examination is a mandatory requirement for the confirmation of odontomes as the diagnosis cannot be made by visual or manual procedures. The treatment is usually the surgical removal of odontomes. ${ }^{7}$ So, the surgical removal was done under local anesthesia, but one small odontome was intentionally left as it was approximating the mesial root of 36 which was in accordance with the finding reported by previous studies supporting the fact that asymptomatic odontomes without any clinical manifestations can be left within the bone for many years and surgery can be deferred. ${ }^{2,21,22}$ On the other side, dentigerous cyst and calcifying epithelial odontogenic cysts are also reported in a few intentionally left asymptomatic odontomes. ${ }^{2}$ The histological reports of our case confirmed that it was both composite and complex odontomes.

\section{Conclusion}

- Pediatric patients with a history of delayed eruption or clinically missing tooth should be thoroughly inspected visually, manually, and radiographically for odontomes as a reason for delayed eruption or missing tooth.

- Odontomes are benign lesions that may be excised under local anesthesia during 1-day surgery.

- Early diagnosis of odontomas can help a pedodontist or clinician to adopt a less complex and less expensive approach.

\section{References}

1. Katiyar A, Gupta K, Solanki S, et al. A case of dental hamartoma associated with unerupted primary canine in maxillary region. Natl J Maxillofac Surg 2018;9(2):232-234. DOI: 10.4103/njms.NJMS_22_18. 
2. Bereket C, Çakır-Özkan N, Şener I, et al. Complex and compound odontomas: analysis of 69 cases and a rare case of erupted compound odontoma. Nig J Clin Practice 2015;18(6):726-730. DOI: 10.4103/11193077.154209.

3. Buchner A, Merrell PW, Carpenter WM. Relative frequency of central odontogenic tumors: A study of 1,088 cases from Northern California and comparison to studies from other parts of the world. J Oral Maxillofac Surg 2006;64(9):1343-1352. DOI: 10.1016/j. joms.2006.05.019.

4. Ochsenius G, Ortega A, Godoy L, et al. Odontogenic tumors in Chile: a study of 362 cases. J Oral Pathol Med 2002;31(7):415-420. DOI: 10.1034/j.1600-0714.2002.00073.x.

5. Machado C, de V, Knop LAH, et al. Impacted permanent incisors associated with compound odontoma. BMJ Case Rep 2015(jan09 3), DOI: 10.1136/bcr-2014-208201.

6. Tuczyńska A, Dariusz B, Yasmin A-F, et al. Compound odontoma in the mandible. Case study and literature review. Dev Period Med 2015;XIX(4):484-489.

7. Satish V, Prabhadevi MC, Sharma R. Odontome: a brief review. Int J Clin Pediatr Dent 2011;4(3):177-185. DOI: 10.5005/jp-journals-10005-1106.

8. Venigalla A, Guttikonda LK, Nelakurthi H, et al. Ectopic compound odontoma in the buccal mucosa: report of a rare case. Case Rep Dent 2015. 1-4. DOI: 10.1155/2015/835171.

9. Garvey MT, Barry HJ, Blake M. Supernumerary teeth - an overview of classification, diagnosis and management. J Cand Assoc 1999;65(11):612-616.

10. Junquera L, de Vicente JC, Roig P, et al. Intraosseous odontoma erupted into the oral cavity: an unusual pathology. Med Oral Patol Oral Cir Bucal 2005;10(3):248-251.

11. Zoremchhingi Joseph T, Varma B, et al. A compound composite odontoma associated with unerupted permanent incisor-a case report. J Indian Soc Pedod Prev Dent 2004;22:114-117.
12. Hanemann JA, Oliveira DT, Garcia NG, et al. Peripheral compound odontoma erupting in the gingival. Head Face Med 2013;9(1):15. DOI: 10.1186/1746-160X-9-15.

13. Shafer GW, Hine MK, Levy BM. A textbook of oral pathology, In: Rajendran R, ed. 4th ed., US, Philadelphia: WB Saunders; 1983. pp. 308-311.

14. Brunetto AR, Turley PK, Brunetto AP, et al. Impaction of a primary maxillary canine by an odontoma: surgical and orthodontic management. Pediatr Dent 1991;13(5):301-302.

15. Amailuk P, Grubor D. Erupted compound odontoma: Case report of a 15-year-old Sudanese boy with a history of traditional dental mutilation. Br Dent J 2008;204(1):11-14. DOI: 10.1038/bdj. 2007.1184.

16. Odontomes SE. Br Dent J 1937;62:177-201.

17. Kharbanda OP, Saimbi CS, Kharbanda R. Odontome: a case report. J Indian Dent Assoc 1986;58(6):269-271.

18. Mosqueda-Taylor A, Ledesma-Montes C, Caballero-Sandoval S, et al. Odontogenic tumors in Mexico: a collaborative retrospective study of 349 cases. Oral Surg Oral Med Oral Pathol Oral Radiol Endod 1997;84(6):672-675. DOI: 10.1016/S1079-2104(97)90371-1.

19. Boffano P, Zavattero E, Roccia F, et al. Complex and compound odontomas. J Craniofac Surg 2012;23:685-688.

20. Teruhisa U, Murakami J, Hisatomi M, et al. A case of unerupted lower primary second molar associated with compound odontoma. Open Dent J 2009;3(1):173-176. DOI: 10.2174/1874210600903010173.

21. Fernandes AM, Duarte ECB, Pimenta FJGS, et al. Odontogenic tumors: a study of 340 cases in a Brazilian population. J Oral Pathol Med 2005;34(10):583-587. DOI: 10.1111/j.1600-0714.2005.00357.x.

22. Batra $P$, Duggal $R$, Kharbanda OP, et al. Orthodontic treatment of impacted anterior teeth due to odontomes: a report of two cases. J Clin Pediatr Dent 2004;28(4):289-294. DOI: 10.17796/jcpd.28.4.f2114 718u87u4712. 